\title{
Quality of Life and Impressions of Quality of Life of Migrants to Chennai: A Factor Analysis Approach
}

\author{
${ }^{1}$ K.Vinayakam, ${ }^{2}$ S.P.Sekar \\ ${ }^{1}$ Research Scholar, Department Of Planning, Sap, Anna University, Chennai. \\ ${ }^{2}$ Professor, Department of Planning, SAP, Anna University, Chennai
}

\begin{abstract}
This paper has the purpose of assessing quality of life of migrants of Chennai city using 14 variables measured with Likert-type of scaling in a factor analysis. As many as 305 randomly chosen migrant-respondents from across the city have been interviewed using a custom-designed, structured questionnaire in 2012. The analysis has yielded two very neat and significant factor dimensions, labeled as 'Quality of Life Dimension' and 'Well-being in Life and Work Dimension'. The two factors, retained in the analysis using the eigenvalue criterion, explain a cumulative variance of 49.434 per cent. The rotated factor scores have shown that 47.4 per cent of the migrants of Chennai are on the better side of quality of life whereas 45.6 per cent of them are on the higher side of well-being in their life and work. In their revealed perceptions of quality of life and well-being in life and work, there is yet much to be accomplished and there are challenges in city life they could face up to.

Keywords: Quality of life, Well-being, Life and work, Megacities, Urbanization, Migrants of Chennai, Factor Analysis Approach
\end{abstract}

\section{Introduction}

A more realistic vision of future population flows concerns migration to and from cities. In 2008 , half of the world's population was in urban areas. Most of the expected population growth over the next few decades will be predominantly urban, and basically concentrated in cities of the developing world (Haydea Izazola and Alan Jowett, 2008, www.populationenvironmentresearch.org/seminars.jsp). One third of these cities' population lives in slums, with precarious housing and limited or nonexistent access to basic services. The crowded cities also suffer from severe air pollution, which affects not only the urban poor, but urban populations in general. These cities are also expected to suffer the effects of climate change in the future. For most people in urban areas quality of life has been threatened (for example, Cutter 1985; Hemmasi, 1994; 1995). Different aspects quality of life assume varying degrees of importance when it comes to migration processes.

Quality of life is an active arena for interdisciplinary research, attracting scholars from planning, geography, sociology, political science, economics, and other disciplines. Helburn (1982:445) has asserted that because 'quality of life' as a policy goal is attached to place, it is a goal of which spatial scientists must be cognizant, and to which planners and geographers can make important contributions. Cutter (1985) drew attention to the subject of quality of life in her monograph, 'Rating Places: A Geographer's View on Quality of Life'. Awareness of spatial and temporal variations in the quality of life can enable policy makers and planners to monitor changes and to devise more effective policies to address persisting inequalities (Hemmasi, 1994; 1995).

Numerical and statistical methodology for creating comparative quality of life indexes is still evolving. Techniques for developing composite quality of life indexes include simple rankings of places, calculation of standard scores, scaling methods, and factor or principal components analysis (Dasgupta and Wea1e, 1992; Park, 1985; Hall, 1984; Tata and Schultz, 1988; Stover and Leven, 1992; Ram, 1982).

For some migrants to the cities, especially for the poorest and the less educated, their priority may be for guaranteeing an income to sustain their families, while neglecting quality of life concerns. In most cities of the developing countries, people live with little or no concern for quality of life; yet it is largely for the reason of improving their lives, towards a certain level of quality of life, migrants have left their safer homes behind and have suffered in unimaginable ways in the cities before they could actually make some quality out of their lives and work.

Quality of life has been an evolving field of research, in which several conceptual identification and empirical measurement problems exist. So-called 'objective' socioeconomic variables, such as educational attainment and median income are relatively widely published for geographical areas and social groups. However, quality of life as a concept also evokes 'subjective' perceptual or valuative aspects of human existence which are less commonly reported. The current study is devoted to such a subjective, perceptual aspects of urban life and work, in Chennai city. The effort in this paper is however less towards developing an index of quality of life but more towards understanding what the migrants of Chennai City think, and perceive, of their quality of life and whether or not it has improved in their perceived notions of their life and work. For 
statistical and substantive reasons, findings at one scale (individuals, migrants) need not apply without revision to other scales (say, communities and neigbourhoods).

\section{Urbanization and Migration in Megacities of India}

Of growing concern are the country's teeming new megacities, which are swelling rapidly even as jobs dry up and funding for infrastructure disappears (Patrick Barta and Krishna Pokharel, India News in The Wall Street Journal, May 13, 2009). Across India, poor migrants keep streaming into cities like Chennai, many of which are woefully mismanaged and ill-equipped to handle the influx. India has at least 41 cities with more than one million people, up from 23 two decades ago. A half dozen others have joined the megacity list in 2011 (Census of India 2011). Urban experts say the risk is now rising that some of these cities could face the same fate as Mumbai and Kolkata, which became synonymous with poverty and decay in the 1970s and 1980s. The country already has 25 of the world's 100-fastest growing urban areas, according to City Mayors, an international urban-affairs think tank. That compares with eight in China. Pune, near Mumbai, has more than four million people, about the same as the Houston area. Kanpur, in north central India, has more than three million, as does Surat, in western India. India is expected to add 10 million people a year between 2000 and 2030 to its 5,161 cities, according to the United Nations.

The Jawaharlal Nehru National Urban Renewal Mission was launched in 2005 by the national government to help more than 60 major cities by spending US $\$ 10$ billion to upgrade sewers, water supply, roads and other necessities. But that falls far short of the US \$ 52 billion the government estimates it will take to fix India's urban infrastructure. Chennai, like many other Indian cities, is managed by a bewildering array of government bodies that do not always coordinate activities very well. In theory, Chennai is led by an elected mayor and 155-member City Corporation, similar to a U.S. city council. Together, they share oversight of basic services such as water, housing and roads. But in practice, the elected officials' authority is sharply limited by the half-dozen or more other government bodies that wield power in town. Chief among them is the Chennai Metropolitan Development Authority, a group of unelected bureaucrats who have the authority to develop new housing projects and roads within them. But after a few years, when the developments are completed, the CMDA hands over management of the projects to the City Corporation, which does not always have enough money to maintain basic services such as water, sewage and street lights.

Mobility and migration are a part of development process resorted by people to improve their socioeconomic condition. Migration plays an important role in changing the demographic composition of any country, state, and districts population. It is as important as fertility and mortality. Man can control the fertility and mortality, but in the case of migration, it is difficult to control. We cannot achieve development by stopping or controlling the process of migration. Migration is a social a phenomenon which is influenced by both underdevelopment as well as development. It is found that in Delhi and Mumbai, migrants constitute about 44 per cent of the total population in 2001. This has increased from the earlier figure of 39 per cent in Delhi and 35 per cent in Mumbai in 1991 (also see Bhagat and Mohanty, 2009; Chandra, 2010).

The contribution of migrants to the total population has increased for all the cities except Chennai where it has declined in 2001. The proportion of female migrants to the total female population has also increased in all the cities except Chennai and Hyderabad where it has declined. Total migrants of Chennai dropped from 27.63 per cent in 1991 to 25.03 per cent in 2001. Male migrants to Chennai declined from 27.44 per cent in 1991 to 25.96 per cent in 2001 . The corresponding figures for female migrants were 27.83 per cent in 1991 and 24.06 per cent in 2001.

Sex ratio of the population is an important demographic parameter. Numbers of females per 1000 males is taken as the sex ratio of the population. Urban sex ratio which is highly skewed in favour of males has marginally improved in 2001 in comparison with 1991 except Delhi and Mumbai where it has declined further. The sex ratio among migrants is still more skewed in favour of males than the general population. This is found to be true for all the cities during 2001 Census. It implies that there is a predominance of male migration to these mega cities. In Chennai, sex ratio stood at 933 in 1991 and improved slightly to 950 in 2001, for the general population. But for migrants, there was a reversal of the process, for sex ratio declined drastically from 946 in 1991 to 881 in 2001.

It is found that more than half the female migrants in Delhi (55.2 percent), Mumbai (60.0 percent) and Kolkata (59.0 percent) have been staying in the city for more than ten years in 2001. It is proportionately low for Chennai (40.0 percent), Hyderabad (34.0 per cent) and Bangalore (40 per cent). Recent migration of less than one year duration is between 1.0-2.0 per cent in all the cities. Bangalore has the highest proportion of female migrants (20.0 per cent) of duration 1-4 years followed by Hyderabad (18.6 per cent) and Delhi (17.9 per cent) in 2001. Similarly, the cities having the highest proportion of female migration of duration 5-9 years is Delhi (18.0 per cent) followed by Mumbai (15.7 per cent), Hyderabad (14.0 per cent) and Bangalore (14.0 per cent). The reasons of female migration have been categorized into seven, namely, employment, business, education, marriage, family moved, natural calamities and others in the 1991 Census of India. During 2001 Census, 
however, two reasons, namely, family moved and natural calamities were dropped. Instead two new reasons of moved after birth and moved with household were added during the 2001 Census period. As it is well known, the most important reason for female migration in India is marriage. Census data also show that 46.0 per cent of the females migrate to Mumbai due to marriage followed by Kolkata (38.0 per cent), Bangalore (33.5 per cent), Delhi (33.0 per cent), Chennai (25.2 per cent) and Hyderabad (21.0 per cent) in 2001. The proportion of marriage migration has declined over the period in Delhi, Chennai, and Hyderabad and has increased in Mumbai and Kolkata. It has however remained constant in Bangalore.

The volume of male and female migration has increased in all the six mega cities during 1991 and 2001. The proportion of female migrants to the total female population has increased in all the cities except Chennai and Hyderabad where it has declined. The sex ratio among migrants is still more skewed in favour of males than the general population. Sex ratio of population has increased in six mega cities except Delhi and Mumbai and sex ratio of migrant population is declining in six mega cities except Bangalore during 1991 and 2001 .

The proportion of migration for employment has increased over time in Delhi, Mumbai and Bangalore while it has declined in Kolkata, Chennai and Hyderabad during 1991 and 2001. The proportion of marriage migration has declined over period in Delhi, Chennai, and Hyderabad and has increased in Mumbai and Kolkata. It has remained constant in Bangalore.

Duration of stay in megacities differs from community to community. Most student communities come for four to five years and return home at completion of their studies while those who managed to get job, continue or migrate to other cities. Those who work in Government jobs and private sectors continue to stay until they get retired and return to their native states but this phenomena is likely to change in days ahead due to unrest of socio-political situation in their home states such as the northeastern states, for example. It will also be important to understand what pushes and pulls the northeasterners to megacities and challenges they face (Madhu Chandra, December 08, 2010 in countercurrents.org).

\section{Aim and Objectives}

The aim of this paper is to examine the perceptions of migrants of Chennai city and try to understand how they rate two select components of the urban Chennai, which is one of the six megacities of India today. The objectives of the study however are: (a) to extract two factor dimensions using a dataset, gleaned from a questionnaire survey of 305 migrants to the city from two sections of the questionnaire, namely, (i) evaluation of the feelings relative to the quality of life in the city and (ii) evaluation of the feelings relative to overall impressions of well-being and life and work; and (b) to evaluate how well the basic dimensions of quality of life and overall well-being and life and work of the migrants to Chennai are explainable using a factor analysis approach.

\section{Materials and Method}

The material discussed in the study relates to a small part of a larger study on Life and Work of Migrants of Chennai City. As indicated above the two sections of the custom designed questionnaire are an evaluation of feelings relative to quality of life (in relation to nine simple items) and feelings relative to overall impressions of life and life and work (5 items) using Likert type of scaling as shown below:

\section{A. Overall Quality of Life}

Directions: Evaluate your feelings relative to the quality of life. Using the 1-7 scale below, indicate your choice of scale with each item by placing the appropriate number alongside that item. Please be open and honest in your responding. $(1=$ Terrible; $2=$ Unhappy; $3=$ Mostly dissatisfied; $4=$ Mixed; $5=$ Mostly satisfied; $6=$ Pleased; 7 = Delighted)

1. Your personal life

2. Your wife / husband or 'significant other'

3. Your co-workers

4. The actual work you do

5. The handling of problems in your life

6. Your ability to adjust to change in your life

7. Your life and work as a whole

8. Overall contentment with your life and work

9. The extent to which your life and work have been as you wanted it

\section{B. Overall Impressions of Well-Being and Life and Work}

Directions: Evaluate your feelings relative to the quality of life, using the scale: $(5=$ Better; $3=$ Somewhat better; 2 = Worse) 
1. Overall my physical well-being is

2. Overall my mental and emotional state is

3. Overall my ability to handle stress is

4. Overall my enjoyment of life and work is

5. Overall my quality of life is

\section{Factor Analysis Approach}

Factor analysis is a statistical technique used to examine the interrelations among a set of variables in order to identify the underlying structure of those variables. In essence, it combines (reduces) a set of observed variables into a smaller set of "artificial" variables called 'factors'. It also assumes the dataset to be linear combinations of the variables. In this analysis, large variances have important dynamics. It assumes that factors with larger variance correspond to interesting dynamics and lower ones correspond to noise. Factors are in fact a linear combination of weighted variables. The greatest variance of the dataset is captured by the first axis (called the first factor). The second greatest variance is on the second axis (the second factor) and so on. The factors are uncorrelated since in the sample space they are orthogonal to each other (Rummel, 1970; Davis, 2002).

Variable loadings are the important measures or coefficients that help us interpret the nature of factors. An observed variable "loads" on a factor if it is highly correlated with the factor (has a large eigenvalue). The regression weights (loadings) are determined using a type of equation called an eigen-equation. These weights are optimal because no other set of weights could produce a set of factors that are more successful in explaining the variations in the observed variables. The eigenvalue is a numeric estimation of how much of the variation each factor explains.

There is a term that goes by the word 'communality', which is referred to as $\mathrm{h}^{2}-$ the communality estimate. It measures the percentage of variance in an observed variable accounted for by the retained factors. Thus the variables loading on a factor are validated by their unique or individual variances, while the factors retained are validated by the common variances. Factors with eigenvalues greater than 1.0 are considered important, although at times the researcher can retain a factor with an eigenvalue less than 1.0 for reasons of his or her own.

Fundamentally, principal component and factor analysis are the same, for both analyze correlation matrices. In principal component analysis, all variance of observed variables is analyzed. The interpretation is that the principal components are empirically determined aggregates of the variables without presumed theory. Labels are always used to designate them but they are just a shorthand for the component. Factors, on the other hand, are the underlying (latent) variables that cause the covariation between observed variables: that is, factor analysis produces factors and factors cause variables. The purpose of factor analysis is to identify the latent variables which are contributing to the common variance in a set of measured variables.

Factor analysis is said to be reducing the dimensionality of a problem to a manageable size. However, the meaning of the factors may be difficult to deduce. This problem is overcome by resorting to maximization of the variance of the loadings on the factors. This in other words is maximizing the range of the loadings. This is done in the analysis here by a rotation procedure called Kaiser's varimax rotation. The rotation of the factor axes is performed, iteratively. The analysis also results in factor scores, which represent estimates of the contribution of various factors to each original observation (residents). In fact, factors themselves are estimated from these same data. Thus the computation of factor scores is somewhat a circular process and the results are not unique. Factor analysis explains in a sense the interrelationships in a large number of variables by the presence of a few factors (Kaiser, 1958; Harman, 1960; Lawrence and Upchurch, 1983).

The factor extraction is done with a minimum acceptable eigenvalue of >1.0 (Kaiser, 1958; Harman, 1960). The factor loading matrix is rotated to an orthogonal simple structure, according to varimax rotation. It results in maximization of variance of factor loadings of the variables. This procedure renders a new rotated factor matrix in which each factor is described in terms of only those variables and affords greater ease for interpretation. Factor loading is a measure of the degree of closeness between the variables and the factor. The largest loading, either positive or negative, suggests the meaning of the dimension; positive loading indicates that the contribution of the variables increases with the increasing loadings in a dimension; and negative loading indicates a decrease (Lawrence and Upchurch, 1983).

\section{Quality of Life, Well-being, Life and Work of Migrants of Chennai City}

Using a minimum eigenvalue of 1.0 criterion, the factor analysis of the data matrix (14 variables x 305 cases) yielded two factor solutions. Table 1 below shows the individual variances (communalities extracted) for the 14 variables entered in the analysis. A communality $\left(h^{2}\right)$ is the sum of the squared factor loadings and represents the amount of variance in that variable accounted for by all the factors. For example, the two extracted factors account for 63 per cent of the variance in variable 'your life and work as whole', that is, $h^{2}=$ 0.630 . 
Five of the quality of life variables and just one of the well-being, life and work variables have shown individual variances of more than 50 per cent each. 'Your life and work as a whole' (63 per cent), 'overall contentment with your life and work' (55.7 per cent), 'your personal life' (54.4 per cent), 'actual work you do' (51.9 per cent), and 'your ability to adjust to change in your life' (51.6 per cent) are the most important of the quality of life variables. Although the other four quality of life variables have relatively low communalities extracted, they are not necessarily of low importance in validating the main factor dimension extracted. They do have statistically significant communalities or individual variances: your wife or husband or 'significant other' has a variance of 48.7 per cent whereas 'handling of problems in your life' has 48.3 per cent, 'extent to which your life and work as wanted' has 48.2 per cent and 'your co-workers' has 47.7 per cent. Thus, the migrants perceive that their quality of life has been relatively high in all aspects of quality of life scaled by them.

Table 1: Initial Communalities computed using principal component factor analysis

\begin{tabular}{|l|r|r|}
\hline Variables entered in analysis & Initial & Extracted \\
\hline Your personal life & 1.000 & $\mathbf{0 . 5 4 4}$ \\
Your wife or husband or 'significant other' & 1.000 & 0.487 \\
Your co-workers & 1.000 & 0.477 \\
Actual work you do & 1.000 & $\mathbf{0 . 5 1 9}$ \\
Handling of problems in your life & 1.000 & 0.483 \\
Your ability to adjust to change in your life & 1.000 & $\mathbf{0 . 5 1 6}$ \\
Your life and work as a whole & 1.000 & $\mathbf{0 . 6 3 0}$ \\
Overall contentment with your life and work & 1.000 & $\mathbf{0 . 5 5 7}$ \\
Extent to which your life and work as wanted & 1.000 & 0.482 \\
Your physical well-being & 1.000 & 0.456 \\
Your mental and emotional state & 1.000 & 0.424 \\
Your ability to handle stress & 1.000 & 0.321 \\
Your enjoyment of your life and work & 1.000 & 0.463 \\
Your quality of life & 1.000 & $\mathbf{0 . 5 6 4}$ \\
\hline
\end{tabular}

Extraction method: Principal Component Analysis.

Among the well-being, life and work variables, collectively designated as the 'overall impressions of quality of life,' 'your quality of life' has a unique variance of 56.4 per cent, followed closely but with lesser significance 'your enjoyment of your life and work' with 46.3 per cent, 'your physical well-being' with 45.6 per cent, 'your mental and emotional state' with 42.4 per cent and the variable with the least of the individual variances is 'your ability to handle stress' at 32.1 per cent.

The analysis of data yielded a two-factor solution (Table 2 and Figure 1), in which two interpreted factors together accounted for 49.434 per cent of the total variance in the input data matrix (15 variables x 305 cases).

\section{Factor I: Quality of Life Dimension}

Factor one, the most important dimension, accounted for 27.497 per cent of the total variance and an eigen value of 3.850. This factor can be given substantive interpretation by noting which of the original input variables have the highest factor loadings on this dimension. As shown in Table 3, the variables with high loadings on factor one, such as 'your life and work as a whole' (loading: 0.731; individual variance 63 per cent) and 'actual work you do' $(0.713 ; 51.9$ per cent $)$, indicate that the migrants' life and work as a whole have improved much and the actual work they do speak for their place and quality of life in the city. They are capable of handling the problems in their life (handling problems in your life: $0.695 ; 48.3$ per cent) and, overall, they are contented with their life and work $(0.691 ; 55.7$ per cent). In their own revealed perceptions of their quality of life they have scaled, they do have the ability to adjust to change in their lives $(0.689 ; 51.6$ per cent $)$ and so do they perceive of their co-workers with them $(0.610 ; 47.7$ per cent). 'Your personal life' gets a significant positive loading $(0.525 ; 54.4$ per cent), and similarly the other two variables loading on the factor also have significant and positive loadings: 'extent to which your life and work as wanted' $(0.519 ; 48.2$ per cent) and 'wife or husband or significant 'other', $(0.519 ; 48.7$ per cent $)$. 
Table 2: Total Variance Explained for 2-Factor Matrix

\begin{tabular}{|c|c|c|c|c|c|c|c|c|c|}
\hline \multirow[b]{2}{*}{ Factor } & \multicolumn{3}{|c|}{ Initial Eigenvalues } & \multicolumn{3}{|c|}{$\begin{array}{c}\text { Extraction Sums of Squared } \\
\text { Loadings }\end{array}$} & \multicolumn{3}{|c|}{$\begin{array}{c}\text { Rotation Sums of Squared } \\
\text { Loadings } \\
\end{array}$} \\
\hline & Total & $\begin{array}{c}\% \text { of } \\
\text { Variance }\end{array}$ & $\begin{array}{c}\text { Cumulative } \\
\%\end{array}$ & Total & $\begin{array}{c}\% \text { of } \\
\text { Variance }\end{array}$ & $\begin{array}{c}\text { Cumulative } \\
\%\end{array}$ & Total & $\begin{array}{c}\% \text { of } \\
\text { Varianc } \\
\mathrm{e}\end{array}$ & $\begin{array}{c}\text { Cumulati } \\
\text { ve } \%\end{array}$ \\
\hline 1 & 5.588 & 39.914 & 39.914 & 5.588 & 39.914 & 39.914 & 3.850 & 27.497 & 27.497 \\
\hline 2 & 1.333 & 9.520 & 49.434 & 1.333 & 9.520 & 49.434 & 3.071 & 21.937 & 49.434 \\
\hline 3 & 0.926 & 6.614 & 56.048 & & & & & & \\
\hline 4 & 0.886 & 6.326 & 62.374 & & & & & & \\
\hline 5 & 0.740 & 5.289 & 67.663 & & & & & & \\
\hline 6 & 0.690 & 4.927 & 72.590 & & & & & & \\
\hline 7 & 0.641 & 4.581 & 77.171 & & & & & & \\
\hline 8 & 0.601 & 4.296 & 81.467 & & & & & & \\
\hline 9 & 0.545 & 3.889 & 85.356 & & & & & & \\
\hline 10 & 0.538 & 3.841 & 89.198 & & & & & & \\
\hline 11 & 0.460 & 3.289 & 92.487 & & & & & & \\
\hline 12 & 0.425 & 3.033 & 95.521 & & & & & & \\
\hline 13 & 0.333 & 2.376 & 97.897 & & & & & & \\
\hline 14 & 0.294 & 2.103 & 100.000 & & & & & & \\
\hline
\end{tabular}

Extraction: Principal Component Analysis.

Figure 1: Scree Plot for 2-Factor Matrix Extraction

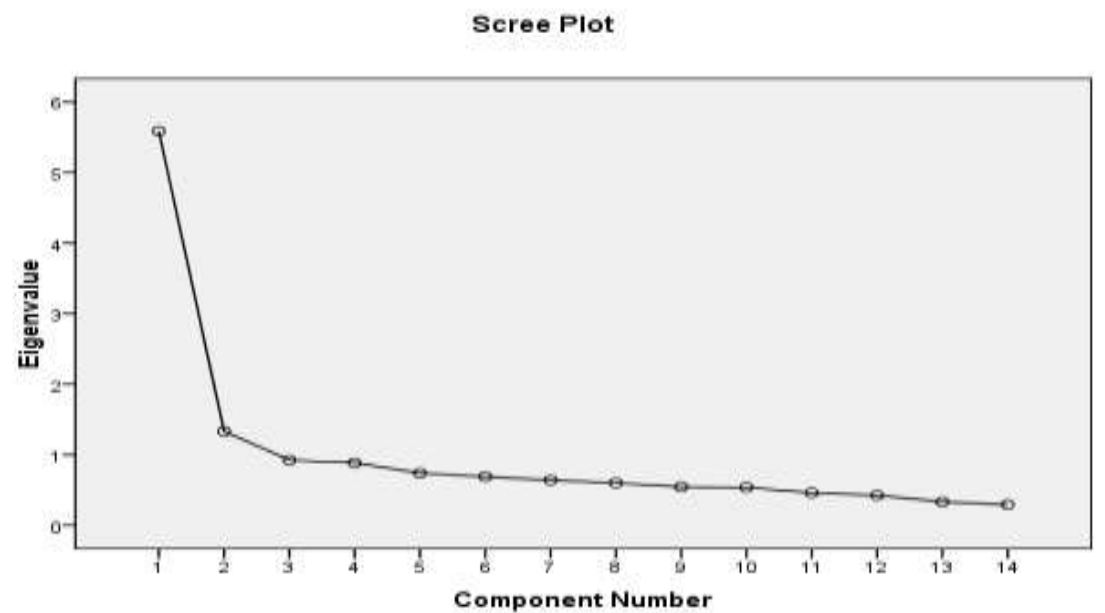

This dimension, named as the Quality of Life Dimension is more distinctive and the patterns of factor one loadings are quite distinctive as well. The migrants, it may be deduced from the rotated factor loadings on the first factor, feel that their 'life and work as a whole' and the 'actual work they do' as most satisfying, even as they say that the other satisfying facts about the quality of life they have achieved as migrants to the metropolitan city are 'they handle problems in their lives' better, they are 'contented with their life and work', and they are able to 'adjust to changes in their lives' better than before. What is more important is that they also see their co-workers in the same situation and light.

They are not definitely alone and their co-workers have done equally better and in the most satisfying ways for them as well. However, in their own 'personal lives', in the 'extent to which their life and work as wanted' and the role of their 'wives or husbands or 'significant others", their success and their feelings are rather mixed than most satisfactory. Overall, therefore, the inference is that, although they have achieved and feel satisfied of their quality of life as migrants of the metropolis, there is yet much to accomplish by way of bringing about a quality of life, which requires probably much effort and time. Fortunately, there is yet space for 
them to do and achieve it, in the given circumstances of the city of Chennai and its growth and development: there is indeed no lack of opportunities to do so in the Chennai milieu and economy.

\section{Factor II: Well-Being in Life and Work Dimension}

Factor two accounts for 21.937 per cent of the total variance. It has a variance of 3.071 in terms of eigenvalue extracted using eigenvector computation. Variables with high loadings on this factor include 'overall quality of life' (loading: 0.745; individual variance explained 56.4 per cent), 'overall physical well-being' $(0.650 ; 45.6$ per cent), and 'overall mental and emotional state' $(0.635 ; 42.4$ per cent). Factor two can be labelled as Well-Being in Life and Work Dimension. The other two variables loading on this factor do indicate not the best of feelings but somewhat better feelings as to the nature of their well-being in life and work in Chennai: 'overall enjoyment of life and work' gets a loading of 0.588 (individual variance explained is: 46.3 per cent) and 'overall ability to handle stress' gets 0.559 as loading and 32.1 per cent as its individual variance explained. This factor, through highly loading variables on it, generally reflects a comparably better quality of life, well-being (physical, mental and emotional) and life and work in the metropolitan city than their places of origin. The migrants have most certainly achieved better prosperity and development in the city milieu and economy. Among the nine overall quality of life variables, 'your personal life' loads on factor two surprisingly with a significant 0.518 which is positive and significant, statistically, for the variable has an individual variance explained at 54.4 per cent. Considering the fact that it loads also on the first factor with a slightly better loading of 0.525 , we deem it to mean that the migrants' 'personal life' variable is significant to occur in both the factors retained and it really means that on both quality of life and well-being in life and work aspects of the migrants their personal life has a greater say.

Table 3: Rotated Factor Matrix Extracted using Varimax Rotation

\begin{tabular}{|l|r|r|}
\hline \multirow{2}{*}{ Variable entered in Analysis } & \multicolumn{2}{|c|}{ Factor } \\
\cline { 2 - 3 } & \multicolumn{1}{|c|}{1} & \multicolumn{1}{|c|}{2} \\
\hline Your life and work as a whole & 0.731 & \\
Actual work you do & 0.713 & \\
Handling problems in your life & 0.695 & \\
Overall contentment with your life and work & 0.691 & \\
Your ability to adjust to change in your life & 0.689 & \\
Your co-workers & 0.610 & \\
Your personal life & 0.525 & 0.518 \\
Extent to which your life and work as wanted & 0.519 & \\
Wife or husband or 'significant other' & 0.515 & \\
Your quality of life & & 0.745 \\
Your physical well-being & & 0.650 \\
Your mental and emotional state & & 0.635 \\
Your enjoyment of life and work & & 0.588 \\
Your ability to handle stress & & 0.559 \\
\hline
\end{tabular}

Extraction Method: Principal Component Analysis.

Rotation Method: Varimax with Kaiser Normalization.

a. Rotation converged in 3 iterations.

As if to quickly repudiate the contention at the end of the interpretation of the first factor retained in the analysis, the migrants of Chennai come strongly and reiterate that their 'overall quality of life' is better as well as their 'physical well-being' and their 'mental emotional state' to take on life's and even work's challenges in the city. The factor also reflects on the ability of the migrants to 'enjoy their life and work' because of the 'overall ability of theirs' to handle stress' and their 'personal life', which has been, albeit unsaid, a means by which they could indeed accomplish the quality of life and well-being in life and work in their years of struggle against odds in the city as migrants.

\section{How do Migrants of Chennai fare in Quality of Life and Well-Being in Life and Work?}

Factor scores are computed to index the relative rankings of cases or the sample of study, migrants of Chennai city in our case, on each of the derived factors. First of all, it is possible to categorize the migrants into 
some definable classes of people in regard to the two factors retained in the analysis for study. A factor, in a simple sense, is a composite variable formed as a linear combination of measured variables. A factor score is a person's score on that composite variable, that is, when their variable values are applied to the factor score formula (Distephano, Zhu and Mindrila, 2009; Comrey and Lee, 1992): usually computed from Z-scores of measured variables, the resulting factor scores are also Z-scores. They have the same properties as the factors they represent. Regression factor scores predict the location of each individual on the factor.

In all, there are both positive and negative rotated factor scores. In the first factor extracted and labelled as Quality of Life Dimension, the minimum rotated factor score is -5.172 and the maximum is 2.802 . On scrutiny, nearly 11 per cent of the respondents have not been ranked and only 89 per cent of the respondents have been ranked. Of those ranked, 47.4 per cent have been ranked with positive rotated factor scores against 41.7 per cent with negative rotated factor scores. This simply means that a majority of 47.4 per cent of the migrants of Chennai could boast of a better quality of life than before by their own admission, while an equally large proportion of them show low quality of life measures. The bottom quartile of the respondents fall below the rotated score of -0.534 while the top quartile of the rotated scores have scores above 0.692. Figure 2 represents the rotated factor scores extracted for ranking the respondents on the basis of the retained dimension, labelled for convenience as Quality of Life Dimension. A deeper analysis of quality of life dimension shows that nearly a third of the migrants of Chennai have significant but low quality of life in their own estimate, 11.4 per cent slightly better but may be labelled as somewhat better quality of life and a miniscule of 0.6 per cent of them alone have higher, more better and significant quality of life achieved in the life and work in Chennai. Note that a majority is on the positive side of the graphics. Yet a high and significant proportion of them perceive that their quality of life has to be very greatly improved.

Figure 2: Distribution of Rotated Factor Scores - Factor I

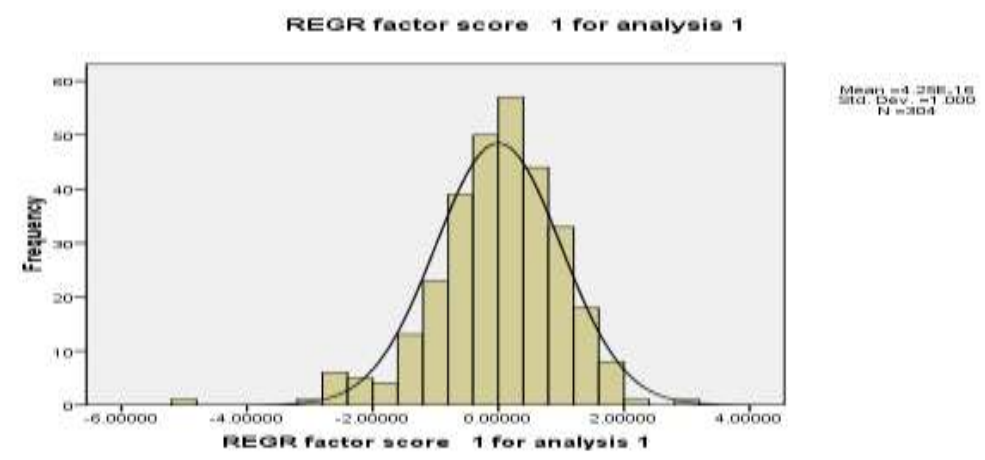

Similarly for factor two, as much as 45.6 per cent of the migrants of Chennai have been scored positively while 43.5 per cent of them are scored negatively. Yet again, most migrants of the city are better placed in regard to factor two, which is Well-being in Life and Work. While the minimum of the rotated factor scores is -2.361 , the maximum is 2.236 . The median percentile is below -0.748 , first percentile is 0.041 and the third percentile is 0.766. Figure 3 represents the rotated factor scores of the factor two retained.

Figure 3: Distribution of Rotated Factor Scores - Factor II

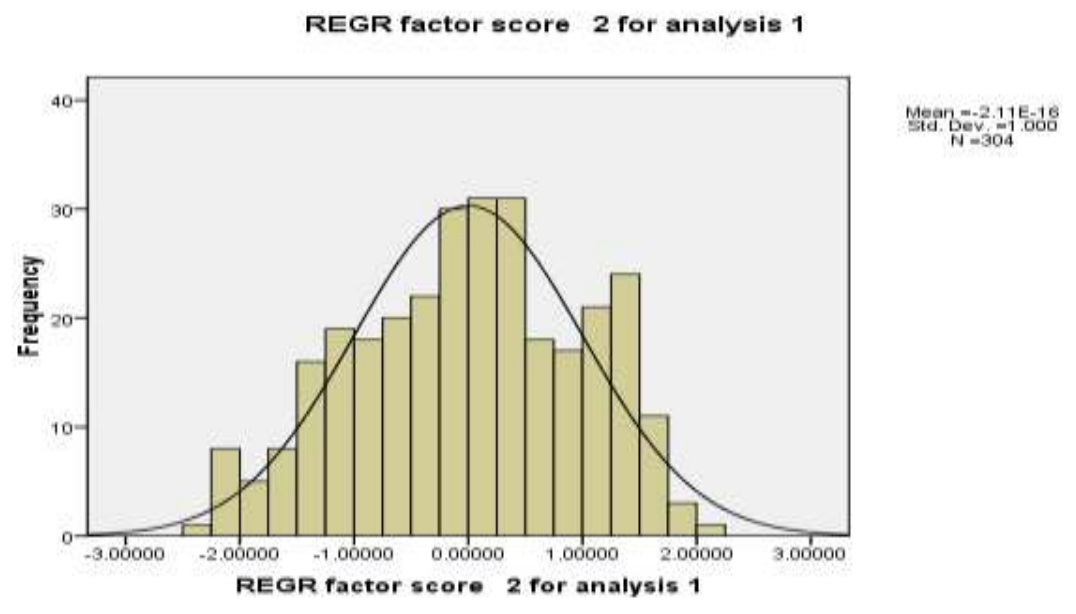


A deeper scrutiny of the rotated factors for the factor two shows that nearly 29 per cent of the migrants of Chennai show up significantly low well-being in life and work, 16.5 per cent of represent a moderate level of well-being in life and work and a tiny proportion of them ( 0.3 per cent) higher levels of well-being in life and work. As in the first factor, there is still a large proportion of migrants of Chennai who must make a breakthrough in their well-being in life and work, as they are yet placed adversely in the city. Note the graphics and the near normal distribution of the migrants on the factor labelled Well-Being in Life and Work.

\section{Conclusion}

This paper has used a factor analytical approach to assessing quality of life and impressions of quality of life of migrants of Chennai city. The dataset has consisted of 14 variables, 9 overall quality of life and 5 overall impressions of quality of life variables, and has been used in the analysis to extract just two factor dimensions. Factor analysis is typically used to confirm the latent factor structure for a group of measured variables. Latent factors are unobserved variables which typically cannot be directly measured; but, they are assumed to cause the scores we observe on the measured or indicator variables. It is a model based technique. It is concerned with modelling the relationships between measured variables, latent factors, and error. The two factors retained in the analysis has provided two neat factors, labelled as Quality of Life Dimension and WellBeing in Life and Work Dimension using the variables highly loading on the factors. The neatness of the analysis could be appreciated because of the fact that the 9 variables of overall quality of life load on the main Quality of Life Dimension and the 5 variables of the overall impressions of quality of life load on the bipolar Well-Being in Life and Work Dimension. The two dimensions do allow the readers an appreciation of the following facts: The migrants feel that:

\section{- Factor One:}

- Their 'life and work as a whole' and the 'actual work they do' are most satisfying.

- The other satisfying facts about the quality of life they have achieved as migrants to the metropolitan city are 'they handle problems in their lives' better, they are 'contented with their life and work', and they are able to 'adjust to changes in their lives' better than before.

- What is more important is that they also see their co-workers in the same situation and light.

- Factor Two:

- The migrants of Chennai come strongly and reiterate that their 'overall quality of life' is better.

- Their 'physical well-being' and their 'mental emotional state' to take on life's and even work's challenges in the city. They also reflect an ability to 'enjoy their life and work' because of the 'overall ability of theirs' to handle stress' and their 'personal life'.

- They could accomplish their present quality of life and well-being in life and work only through years of struggle against odds in the city as migrants.

Factor analysis has been used as an exploratory analysis to categorically conclude how best are the quality of life and well-being in life and work of migrants of Chennai city. The conclusion is that the migrants have done commendably well and achieved a greater and better semblance of an overall quality of life (47.4 per cent of the migrants) and a well-being in their life and work (45.6 per cent of them). They have also sacrificed a lot in their personal lives to achieve and to reach a greater feeling of achievement in them. The implication of the study is that the migrants are greatly focused on achieving a state of quality of life and well-being (physical, mental and emotional state) and they are on their way to achieving them. Nearly half of them are yet to make their mark in regard to both the dimensions, quality of life as well as well-being, as there are yet challenges of urban life to overcome and succeed.

References

[1] Barta, P. and Pokharel, K. 2009: Megacities threaten to choke India, India News in The Wall Street Journal, May 13, 2009 (Wednesday India Edition).

[2] Bhagat, R. B., and Mohanty, S. (2009): Emerging Patterns of Urbanization and the Contribution of Migration in Urban Growth in India, Asian Population Studies, 6 (1): 5-20.

[3] Census of India (1991) India, C-Series, Socio- Economic tables, etc, Registrar General and Census Commissioner's Office, New Delhi, Various Volumes.

[4] Census of India (1991) India, D-Series, Migration tables, etc, Registrar General and Census Commissioner's Office, New Delhi, Various Volumes.

[5] Census of India (2001) India, C-Series, Socio- Economic tables, etc, Registrar General and Census Commissioner's Office, New Delhi, Various Volumes.

[6] Census of India (2001) India, D-Series, Migration tables, etc, Registrar General and Census Commissioner's Office, New Delhi, Various Volumes.

[7] Chandra, Madhu (2010): Northeast migration and challenges in megacities, December 08, 2010: countercurrents.org.Comrey, A.Land Lee, H.B. (1992): A first course in factor analysis, Hillside, NJ: Erlbaum.

[8] Cutter, S. L. (1985): Rating places: A geographer's view on quality of life, Washington, DC: Association of American Geographers

[9] Dasgupta, P. and Weale, M. (1992): On measuring the quality of life, World Development, 20: 119-31. 
[10] Davis, J. C. (2002): Statistics and data analysis in geology, New York: John Wiley.

[11] Distephano, C., Zhu, M. and Mindrila, D. (2009): Understanding and using factor scores: Considerations for the applied researcher, Practical Assessment, Research and Evaluation, a peer-reviewed electronic journal, 14(20): 1-11 ISSN 1531-7714. Available online at: http//pareonline.net/getvn.asp?v=14\&n=20.

[12] Hall, C. (1984): Regional inequality in well-being in Costa Rica, Geographical Review, 74:48-62.

[13] Harman, H.H. (1960): Modern factor analysis, Chicago: Chicago University Press.

[14] Helburn, N. (1982): Geography and the quality of life, Annals of the Association of American Geographers, 72:445-456.

[15] Hemmasi, M. (1994): A multivariate analysis of quality of life in North Dakota, Proceedings of the North Dakota Academy of Science 48: 44.

[16] Hemmasi, M. (1995): Multivariate analysis of quality of life and migration North Dakota, Great Plains Research - A Journal of Natural and Social Sciences, 5(Fall): 283-308.

[17] Izazola, H. and Jowett, A. (2008): Migration, environment and quality of life, a Panel contribution to the Population-Environment Research Network, Cyberseminar on Environmentally Induced Population Displacements (August 2008), www.populationenvironmentresearch.org/seminars.jsp

[18] Kaiser, H.F. (1958): The varimax criterion for analytic rotation in factor analysis, Psychometrica, 23:187-200.

[19] Lawrence, F. W. and Upchurch, S.B. (1983): Identification of recharge areas using geochemical factor analysis, Groundwater, 20 : 680-687.

[20] Park, S. (1985): Quality of life in Illinois counties, Growth and Change: A Journal of Urban and Regional Policy, 16: 56-69.

[21] Ram, R. (1982): Composite indices of physical quality of life, basic needs fulfilment and income: A principal component representation, Journal of Development Economics, 11:227-248.

[22] Rummel, R. 1. (1970): Applied factor analysis, Evanston: Northwestern University Press.

[23] Stover, M. E. and Leven, C. L. (1992): Methodological issues in the determination of the quality of life in urban areas, Urban Studies 29:737-54.

[24] Tata, R. 1. and Schultz, R.R. (1988): World variation in human welfare: A new index of development status, Annals of the Association of American Geographers 78:581-93. 